Errata de

\title{
Locus de controle: validação de uma escala em situação de treinamento
}

[Estudos de Psicologia, 9(3), 441-450]

\author{
Gardênia Abbad \\ Pedro Paulo Murce Meneses \\ Universidade de Brasília
}

No artigo acima o conteúdo da Figura 1 (p. 445) foi publicado com incorreções.

A forma correta é agora reproduzida no verso. 
Descrição do instrumento final

A versão final do instrumento requeria que os respondentes julgassem, um a um, 12 itens, relacionandoos a três fontes predeterminadas: sorte, outros e o próprio indivíduo. A escala de respostas era do tipo Likert de 5 pontos, como descrito anteriormente. Antes de responder aos questionários, os participantes deveriam ler algumas orientações, reproduzidas a seguir, referentes à pesquisa e à forma de avaliação. A Figura 1 traz um exemplo de como os itens foram apresentados aos participantes nas instruções. No primeiro campo, constava a descrição do item e nas três colunas seguintes, havia espaço em branco para que o treinando registrasse os códigos numéricos que correspondessem às suas avaliações da importância das três fontes de controle em cada item.

A instrução para a aplicação do instrumento foi a que segue:

Os itens seguintes referem-se às crenças sobre as fontes que controlam a vida das pessoas nos campos social, afetivo e profissional. Gostaríamos que você emitisse sua opinião sobre o quanto cada uma das três fontes - sorte, outros poderosos, você mesmo - controla a sua vida. Para responder a cada item, registre em todas as colunas à direita das afirmativas os valores numéricos correspondentes à sua opinião, usando, para isso, a escala abaixo.

\begin{tabular}{|c|c|c|c|c|}
\hline 1 & 2 & 3 & 4 & 5 \\
\hline Pouquissimo & Pouco & Mais ou menos & Muito & Muitissimo \\
\hline
\end{tabular}

Veja o exemplo:

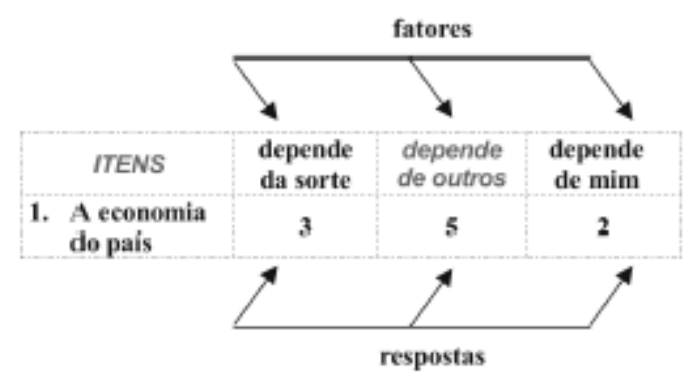

Figura 1. Exemplo de apresentação dos itens do instrumento de locus de controle.

\section{Procedimentos de coleta e análise de dados}

O questionário de locus de controle foi utilizado em pesquisas na área de avaliação de treinamento, nas três organizações mencionadas anteriormente. Era aplicado no $1^{0}$ dia dos cursos avaliados, conjuntamente com questionários que colhiam informações acerca do nível de auto-eficácia dos treinandos, suas expectativas de suporte à transferência pós-treinamento e alguns dados pessoais. A aplica- ção era coletiva e os questionários eram respondidos por todos os participantes antes de o instrutor dar início à exposição dos conteúdos e após breve explicação sobre a pesquisa pelos aplicadores.

As respostas válidas aos 12 itens de locus foram primeiramente submetidas a análises descritivas e de cunho exploratório a fim de avaliar, no arquivo de dados, a distribuição de dados omissos, características das distribuições de freqüência das variáveis, identificação de casos extremos, além da análise de pressupostos como normalidade, multicolineariedade e singularidade, requeridos pela análise fatorial.

Foram realizadas análises dos componentes principais (Principal Components), para estimar o número de fatores e fatorabilidade da matriz de correlações. Esta última foi avaliada pelo índice $K M O$ e inspeção das medidas de adequação da amostra (MAS). Utilizaram-se os seguintes critérios para a tomada de decisão referente à quantidade de fatores a serem extraídos: valores próprios superiores a 1; análise do scree plot; porcentagem mínima de 3\% de variância explicada pelo componente; cargas fatoriais superiores a 0,30. Em seguida, efetuaram-se análises fatoriais (Principal Axis Factorial), a fim de definir a estrutura fatorial do instrumento. Foram incluídos nos fatores os itens com cargas fatoriais superiores a 0,30, teoricamente interpretáveis e com índices de confiabilidade superiores a 0,70. Utilizou-se a técnica de rotação oblíqua (Oblimin). Em ambas as análises, como a quantidade de respostas em branco aos 12 itens analisados não ultrapassou a margem de 5\%, adotou-se o tratamento pairwise, conforme recomendam Tabachnick e Fidell (2001).

Por fim, para se investigar as relações entre as variáveis pessoais estudadas e os fatores de locus de controle, realizaram-se análises de diferenças entre médias (teste $t$ para amostras independentes). Essas análises permitiram determinar se o perfil demográfico dos respondentes estava relacionado às dimensões de locus.

\section{Resultados}

Entre as respostas dos 1.845 participantes da amostra aos 12 itens do instrumento de locus de controle, detectouse a presença de 234 respostas consideradas valores extremos univariados e 95 casos caracterizados como valores discrepantes multivariados.

As análises dos componentes principais e fatoriais foram então realizadas com dois arquivos distintos. No primeiro, mantiveram-se as respostas discrepantes univariadas e os casos que continham valores discrepantes multivariados. Neste caso, a melhor solução empírica encontrada foi formada por três fatores, de acordo com as três fontes de controle utilizadas (Internalidade, Externalidade/Sorte e Externalidade/ Outros). No segundo arquivo de dados, excluíram-se tanto os valores discrepantes univariados como os multivariados. Com a exclusão, duas soluções emergiram.

A primeira era composta por três fatores, como no caso do primeiro arquivo de dados. A segunda solução continha apenas dois fatores (Internalidade e Externalidade). Em am- 